\title{
Effect of packing pH values on the crumbliness of fresh Turkish White cheese
}

\author{
T. Pamuksuz, K. Bulduk, (1) and M. Ozturk* (요 \\ Department of Food Engineering, Sakarya University, Esentepe Kampüsü, Serdivan, Sakarya, Turkey 54187
}

\begin{abstract}
A significant amount of Turkish White cheese is still produced in 1-kg cheese blocks and distributed to retail stores and farmers markets in 18-kg tin containers with brine. Portioning the cheese for the customer's desired weight requires a slicing process. The crumbs that occur during cutting or portioning are undesirable for customers and can cause economic loss for the business. In this study, our goal was to investigate the sliceability of White cheese that was manufactured at various final packing (i.e., packing with brine) $\mathrm{pH}$ values $(5.3,5.0$, 4.7). For this purpose, we manufactured 4 batches of cheese at different times from high heat-treated milk $\left(78^{\circ} \mathrm{C}, 8 \mathrm{~min}\right)$ and monitored the chemical and textural properties at 1,2,4, and $8 \mathrm{wk}$. Cheeses that were packed at $\mathrm{pH} 4.7$ were harder compared with cheeses that were packed at $\mathrm{pH} 5.0$ and 5.3. No correlation was observed between cheese-packing $\mathrm{pH}$ values and the size of the crumbs; however, there was a significant negative correlation between packing $\mathrm{pH}$ and crumb weight (i.e., decrease in cheese-packing $\mathrm{pH}$ increased the crumb weight). Cheeses packed at $\mathrm{pH} 5.0$ and 5.3 exhibited increased slicing adhesiveness during storage. All cheese samples exhibited similar colloidal calcium phosphate levels and water-soluble nitrogen values during storage. This study showed that an increase in the packing $\mathrm{pH}$ of White cheese reduced the weight of crumbs that occurred during cutting. This study is the first study to investigate crumbs occurring with slicing in White cheese. This is also the first study in the literature that monitored the colloidal calcium phosphate content of Turkish White cheese.
\end{abstract}

Key words: Turkish White cheese, cheese crumb, packing $\mathrm{pH}$

Received March 29, 2020

Accepted June 22, 2020.

*Corresponding author: ozturkm@sakarya.edu.tr

\section{INTRODUCTION}

Turkish White cheese is the most consumed cheese in Turkey and comprises 60 to $80 \%$ of the total cheese manufactured in Turkey (Hayaloglu et al., 2002). There are 2 basic types of Turkish White cheese: classical and fresh (cultured). Classical White cheese is manufactured with raw milk (thermization may be applied) without any additional starter culture and ripened at least 3 mo before reaching market. In the manufacturing of fresh White cheese, heat treatment is applied to cheese milk (generally at a temperature higher than pasteurization conditions) to increase the yield, and lactic acid starter cultures are added. Fresh White cheese is sent to the retail stores immediately after manufacturing without ripening, mostly in 0.5- and 1-kg containers. However, some small and medium size manufacturers still use rectangular tin can packages $(18 \mathrm{~kg})$ for fresh White cheese. Cheese blocks $(\sim 1 \mathrm{~kg})$ are placed into the container with brine and shipped, and final portioning is done in retail stores according to the customer's desired weight. The cheese block is exposed to several physical stresses during portioning such as handling and cutting, which may lead to break down of the cheese block into large pieces or the occurrence of smaller size cheese crumbs. For classical White cheese, brittle texture of the cheese is considered a positive quality for customers, as it indicates longer ripening time and lower moisture content. On the other hand, brittle texture of fresh White cheese is unwanted, primarily by the retail stores, as it is hard to cut the main cheese block into smaller portions without losing weight as crumbs. Although crumbs from similar cheese varieties (e.g., Feta) have consumer acceptance and are commercially produced in some countries for ingredient purposes, White cheese crumbs that occur during slicing have no economic value.

Cheese texture is primarily affected by the composition, rate of proteolysis, $\mathrm{pH}$ value, total $\mathrm{Ca}$ content and position (soluble or colloidal), salt content, interactions between casein and serum proteins, and cheese manufacturing protocol (Lucey et al., 2003). The final $\mathrm{pH}$ values of cheese and rate of acid development affect cheese texture directly by changing the electrostatic 
interactions and indirectly by changing the mineral equilibrium (i.e., proportion of soluble and insoluble calcium; Lucey et al., 2003).

According to Horne's casein model, 2 types of interactions manage the intermolecular forces in caseins - electrostatic attraction between phosphoseryl residues and calcium phosphate salts, and hydrophobic interactions between hydrophobic sites of caseins (Horne, 1998). As the acid production proceeds in cheese, casein bound colloidal calcium phosphate $(\mathbf{C C P})$ solubilizes, causing weakening in the protein network and, consequently, the cheese becomes softer. However, as the cheese $\mathrm{pH}$ approaches the isoelectric point of caseins, the electrostatic repulsion between caseins decreases, leading to a hard and brittle cheese texture. Overall, the final $\mathrm{pH}$ value has a critical effect on the final textural properties (e.g., hardness, elasticity, adhesiveness, cohesiveness) of cheeses.

Most studies conducted on classical and fresh White cheeses have focused on the relationship between texture and proteolysis (Hayaloglu et al., 2002; Topcu and Saldamli, 2006). The amount of total Ca and CCP is an important factor that determines the texture of fresh cheeses (Sheehan and Guinee, 2004; O'Mahony et al., 2005). The amount of CCP, to our knowledge, has not been monitored in Turkish White cheese or similar cheese varieties (e.g., Feta, UF Feta, Iranian White cheese), and changes in the texture are most often hypothetically interpreted with CCP levels (Wium and Qvist, 1998; Khosrowshahi et al., 2006; Karami et al., 2009; Zoidou et al., 2015). The effect of $\mathrm{CCP}$ on many cheese varieties (e.g., Cheddar, Mozzarella, processed cheese) were previously investigated, but studies that investigated cheeses with $\mathrm{pH}$ values comparable to White cheese are limited (Metzger et al., 2001; Hassan et al., 2004; Lee et al., 2005). Lee et al. (2005) investigated Cheddar cheese samples manufactured with concentrated milk at 2 different final $\mathrm{pH}$ values. They reported that as cheese $\mathrm{pH}$ dropped below $\mathrm{pH} 5.0$, cheese texture became hard and brittle. They also reported that cheeses with $\mathrm{pH}<5.0$ exhibited fractures on the cheese surface and water loss with syneresis.

The $\mathrm{pH}$ value in which White cheese is placed in the container is critical because the cheese undergoes the last critical changes in the texture and composition in the container, and the manufacturer's ability to intervene at this stage is very limited. In this study, our goal was to investigate the occurrence of crumb weights and sizes with slicing for fresh White cheese that was manufactured at 3 different final packing $\mathrm{pH}$ values $(4.7,5.0$, and 5.3$)$.

\section{MATERIALS AND METHODS}

\section{Cheese Manufacture}

Four different batches of fresh White cheese were manufactured over a 4 -mo period. Cheese milk $(3.3 \pm$ $0.2 \%$ protein, $3.5 \pm 0.2 \%$ fat, $12.5 \pm 0.3 \%$ total solids, $0.16 \pm 0.01$ titratable acidity) was pasteurized at $78^{\circ} \mathrm{C}$ for $8 \mathrm{~min}$, cooled to $38^{\circ} \mathrm{C}$, and inoculated with a thermophilic and mesophilic blend of direct vat set cultures (1:1 blend MO1 and TM1; MicroMilk, Cremosano, Italy) at the rate of $10 \mathrm{~g}$ (5 g/starter) per 450 $\mathrm{kg}$ of cheese milk. As pH reached 6.3, a 30\% (wt/vol) solution of $\mathrm{CaCl}_{2}$ was added to cheese milk at the rate of $1 \mathrm{~L} / 450 \mathrm{~kg}$ of cheese milk. At $\mathrm{pH} 6.2$, calf rennet (Naturen; Chr. Hansen, Istanbul, Turkey) was added to cheese milk at the rate of $63 \mathrm{~g} / 450 \mathrm{~kg}$ of cheese milk. After coagulation $(\sim 75 \mathrm{~min}, \mathrm{pH} \sim 6.0)$ the curd was cut, drained, and transferred into 3 separate hoops (with cheese cloth) and pressed $(\sim 1.2 \mathrm{kPa})$. Presses were removed from all hoops as the first cheese reached the targeted $\mathrm{pH}$ value (5.3) to obtain similar moisture content in all experimental cheeses. As the cheese $\mathrm{pH}$ reached the targeted packing $\mathrm{pH}$ levels $(\mathrm{pH}$ 5.3, 5.0, and 4.7), cheeses were cut into small cheese blocks ( 8 $\times 7 \times 5 \mathrm{~cm})$, placed into containers, brined $(11 \% \mathrm{NaCl}$ wt/wt), and packed. Experimental cheeses were stored in the refrigerator at $4^{\circ} \mathrm{C}$ and analyzed at $1,2,4$, and 8 wk.

\section{Compositional Analyses}

Cheese milk was analyzed for protein (total percentage $\mathrm{N} \times 6.38$; Kjeldahl method; method 991.20; AOAC International, 2007), total solids (method 941.08; AOAC International, 2007), fat (method 2000.18; AOAC International, 2007), ash (method 945.46; AOAC International, 2007), pH (Hanna pH211; Hanna Instruments, Woonsocket, RI), and titratable acidity (method 947.05; AOAC International, 2007) on the day of cheese manufacturing. Cheese composition was analyzed for protein, total solids, fat, ash, and salt (method 975.20; AOAC International, 2007) at 1, 2, 4 , and 8 wk of storage. Cheese $\mathrm{pH}$ was monitored using a spear-tip pH electrode (Inlab solid pro; Mettler Toledo, Columbus, OH) during storage. Soluble $\mathrm{Ca}$ in cheese was obtained as described in Pastorino et al. (2003a). Total Ca, total Na, and soluble Ca content of cheeses were analyzed by using inductively coupled argon plasma emission spectroscopy as described in Park (2000). Colloidal Ca content of cheese was calculated by subtracting soluble Ca content from total $\mathrm{Ca}$ as described in Pastorino et al. (2003a). Proteolysis in cheese 
was monitored by analyzing the water-soluble nitrogen (WSN) as described in Kuchroo and Fox (1982) at 1, 2,4 , and 8 wk.

\section{Textural Measurements}

Texture profile analyses (TPA) were measured using a TA.XTPlus Texture Analyzer (Texture Technologies Corp., Scarsdale, NY). Cheese samples were prepared with a cork-borrer to $15 \mathrm{~mm}$ height and $20 \mathrm{~mm}$ diameter and stored in $4^{\circ} \mathrm{C}$ before the analyses. For the TPA test, $30 \%$ strain was applied with a 5 -mm cylindrical probe at the speed of $0.08 \mathrm{~mm} / \mathrm{s}$ (Hwang and Gunasekaran, 2001).

The sliceability (slicing crumbliness) of the cheeses were measured using knife edge probe (HDP/WBV; Texture Technologies Corp.). Cheese blocks with the dimensions $8 \times 7 \times 5 \mathrm{~cm}$ (at the temperature of $4-6^{\circ} \mathrm{C}$ ) were placed on the cutting platform and sliced with the probe at the speed of $20 \mathrm{~mm} / \mathrm{s}$. Cheese blocks were cut 3 times with $2 \mathrm{~cm}$ thickness. Crumbs from each cutting were collected, sorted by size, and weighed.

\section{Experimental Design and Statistical Analyses}

Cheeses were manufactured in 4 replicate cheese making trials. In each trial, cheeses were manufactured with 3 packing $\mathrm{pH}$ values $(5.3,5.0$, and 4.7$)$. We carried out an ANOVA test with JMP (version 11.0, SAS Institute Inc., Cary, NC). Data obtained from analyses were compared with Tukey-HSD multiple comparisons test, and significance was determined at $P<0.05$. Pearson correlation coefficients were estimated between various responses.

\section{RESULTS AND DISCUSSION}

\section{Cheese Composition and Colloidal Calcium Levels}

The general compositions of experimental cheeses are given in Table 1. White cheeses packed at $\mathrm{pH} 4.7$ exhibited higher total solids, thereby a higher protein content compared with the cheeses packed at $\mathrm{pH} 5.0$ and 5.3. The water holding capacity of cheese decreases as the $\mathrm{pH}$ of cheese approaches the isoelectric point of caseins ( $\mathrm{pH} 4.6$; Pastorino et al., 2003b). Holding the curd at a $\mathrm{pH}$ value closer to the isoelectric point during the manufacturing of cheeses packed at $\mathrm{pH} 4.7$ may have helped the curd lose more moisture; thus, cheeses packed at $\mathrm{pH} 4.7$ exhibited a higher total solids content compared with cheeses packed at $\mathrm{pH} 5.0$ and 5.3. After 4 wk of storage, all cheeses exhibited similar total solid contents. No significant differences $(P$
$>0.05)$ were observed in fat, salt, and ash content of cheese samples during storage. The total salt content of cheeses remained within $( \pm 1 \%)$ the latest legislative limits in Turkey (Turkish Codex for Foods, 29261:2015; $6.5 \% \mathrm{NaCl}$ in total solids, wt/wt) and no significant differences were observed in total sodium contents.

Change in $\mathrm{CCP}$ as a percent of total Ca during storage is given in Figure 1. No significant differences $(P$ $>0.05$ ) were observed in CCP levels for White cheeses packed at $\mathrm{pH} 4.7,5.0$, and 5.3. Previous studies reported that the major change in the CCP level of cheese occurred during the first month of storage and ripening; after $1 \mathrm{mo}$, CCP levels in cheeses remained at similar levels during rest of the ripening (Lucey et al., 2003; Hassan et al., 2004). In this study, all cheeses exhibited similar $\mathrm{pH}$ values after 1 wk of storage (Figure 2). The similar $\mathrm{pH}$ values reached at the end of $1 \mathrm{wk}$ of storage may explain similar observed CCP levels during storage. Previous studies reported that CCP levels in cheese reached a minimum of $\sim 40 \%$ during ripening (Hassan et al., 2004; Lee et al., 2005). White cheese has a lower $\mathrm{pH}$ and higher moisture content compared with Cheddar cheese, which might have led to CCP levels dropping lower than $40 \%$ during storage. However, similar to the previous studies, the level of CCP dropped $\sim 40 \%$ for all cheese samples at 4 wk of storage, and remained around this level during storage.

\section{Proteolysis}

Proteolysis is one of the major steps in flavor development, and residual coagulant activity is the main contributor of primary proteolysis in fresh cheeses (Grappin et al., 1985). In this study, primary proteolysis in cheese was monitored by measuring WSN content

Table 1. Composition of White cheeses manufactured with various packing $\mathrm{pH}$ values at $2 \mathrm{wk}$ of storage ${ }^{1}$

\begin{tabular}{lrcc}
\hline & \multicolumn{3}{c}{ Treatment } \\
\cline { 2 - 4 } Item & \multicolumn{1}{c}{$\mathrm{pH} 4.7$} & $\mathrm{pH} 5.0$ & $\mathrm{pH} 5.3$ \\
\hline Moisture (\%) & $59.5 \pm 1.4^{\mathrm{a}}$ & $62.3 \pm 1.6^{\mathrm{b}}$ & $62.7 \pm 1.9^{\mathrm{b}}$ \\
Fat $\%)$ & $20.4 \pm 3.8^{\mathrm{a}}$ & $19.0 \pm 3.4^{\mathrm{a}}$ & $19.7 \pm 3.8^{\mathrm{a}}$ \\
Protein (\%) & $15.2 \pm 1.3^{\mathrm{a}}$ & $12.8 \pm 1.4^{\mathrm{b}}$ & $13.1 \pm 1.7^{\mathrm{ab}}$ \\
Salt $(\%)$ & $2.7 \pm 0.9^{\mathrm{a}}$ & $2.6 \pm 1.0^{\mathrm{a}}$ & $2,7 \pm 1.1^{\mathrm{a}}$ \\
Ash $(\%)$ & $4.7 \pm 0.9^{\mathrm{a}}$ & $4.9 \pm 0.9^{\mathrm{a}}$ & $5.1 \pm 0.6^{\mathrm{a}}$ \\
$\mathrm{Ca}(\mathrm{mg} / 100 \mathrm{~g}$ of cheese) & $302 \pm 12^{\mathrm{a}}$ & $289 \pm 34^{\mathrm{a}}$ & $322 \pm 38^{\mathrm{a}}$ \\
$\mathrm{Na}^{3}(\mathrm{mg} / 100 \mathrm{~g}$ of cheese) & $779 \pm 11^{\mathrm{a}}$ & $841 \pm 12^{\mathrm{a}}$ & $850 \pm 97^{\mathrm{a}}$ \\
\hline
\end{tabular}

$\overline{\mathrm{a}, \mathrm{b}}$ Values within the same row with different superscript letters differ $(P<0.05)$.

${ }^{1}$ Data are means $(\mathrm{n}=4)$.

${ }^{2}$ Determined using Mohr method (975.20; AOAC International, 2007).

${ }^{3}$ Determined using inductively coupled argon plasma emission spectroscopy method (Park, 2000). 


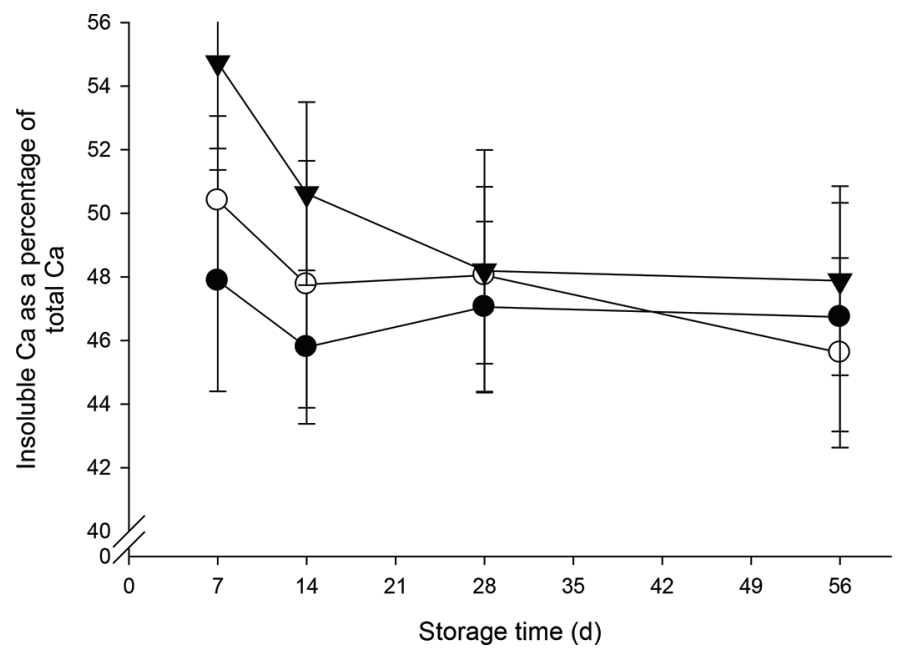

Figure 1. Changes in the percentage of insoluble $\mathrm{Ca}$ as a percentage of total cheese $\mathrm{Ca}$ in White cheeses packed at $\mathrm{pH} 4.7(\bullet), 5.0$ $(\mathrm{O})$, and $5.3(\boldsymbol{\nabla})$ during storage measured by the inductively coupled argon plasma emission spectroscopy method (Pastorino et al., 2003a). Vertical bars represent standard deviations.

of cheeses. Cheeses at all packing $\mathrm{pH}$ values exhibited similar WSN levels during storage (Figure 3). The source of coagulant, amount of coagulant, and cheese environment (e.g., pH, salt in moisture; $\mathbf{S M}$ ) are the main factors that contribute to the primary proteolysis in cheese. Salt and moisture content of White cheese samples were within the limits that allow residual coagulant activity. Grappin et al. (1985) reported that residual rennet activity on $\alpha_{S 1}$-casein was at the highest rate at $\mathrm{pH} 5.0$ and $4 \% \mathrm{SM}$, and the activity on $\beta$-casein was unaffected around the isoelectric $\mathrm{pH}$ at $2.5 \% \mathrm{SM}$. They also reported that no para-k-casein breakdown was observed in primary proteolysis (Grappin et al., 1985). Even though the packing $\mathrm{pH}$ value was different for all White cheese samples, cheeses exhibited similar $\mathrm{pH}$ values at the end of $1 \mathrm{wk}$ of storage. The similar composition and $\mathrm{pH}$ values of cheeses should be why we observed similar proteolysis rates in all cheeses.

\section{Cheese Texture}

The hardness results obtained from the TPA of cheeses are presented in Figure 4. Cheese with packing $\mathrm{pH}$ of 4.7 exhibited a harder $(P<0.05)$ texture compared with cheese packed at $\mathrm{pH} 5.0$ and 5.3 (Figure 4). Lucey et al. (2003) reported that cheese exhibits a hard and brittle structure as the $\mathrm{pH}$ value approaches the iso-electric point. In our study, we think that the higher

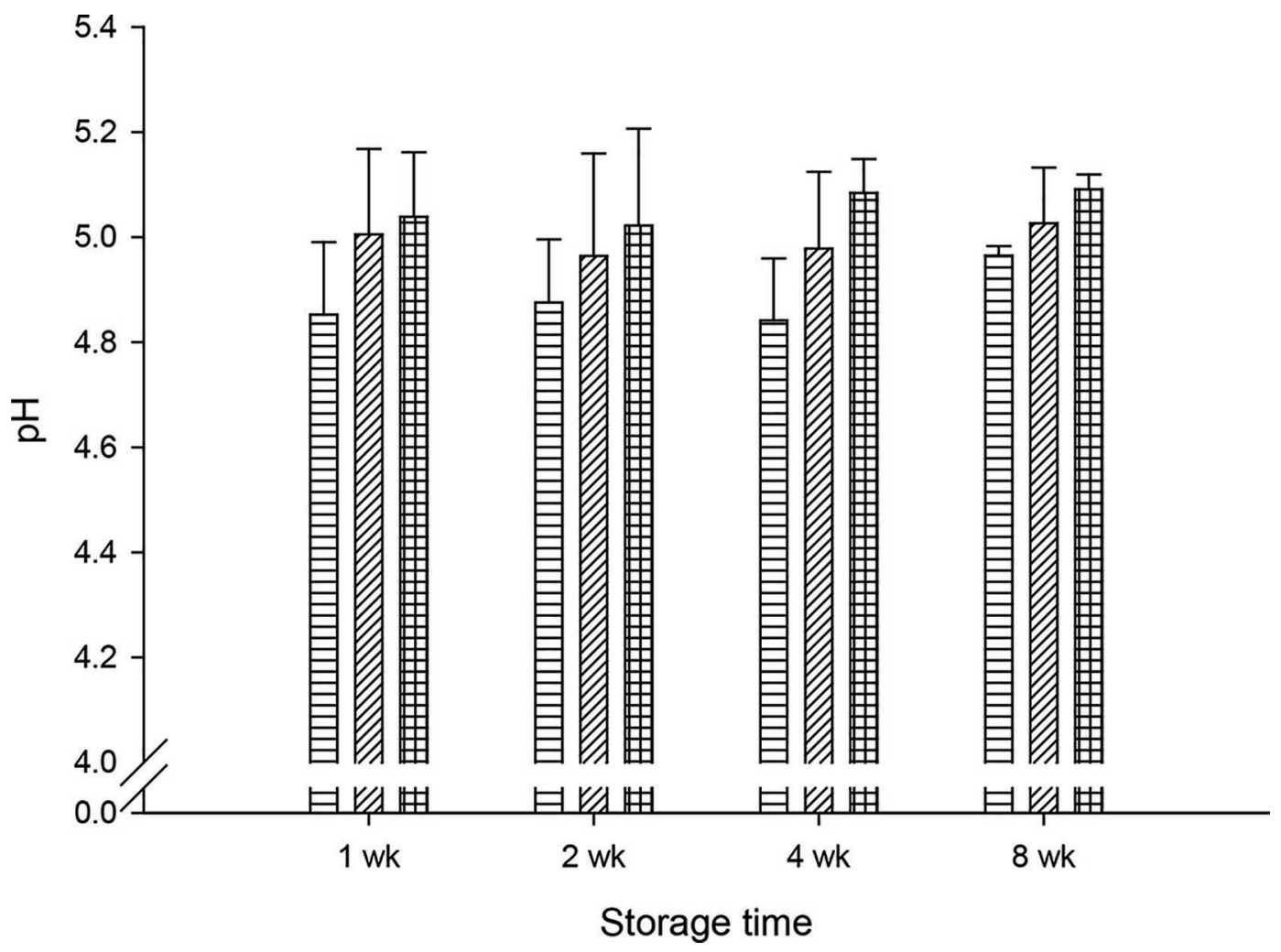

Figure 2. The $\mathrm{pH}$ values for White cheeses packed at $\mathrm{pH} 4.7$ (horizontal lines), 5.0 (diagonal lines), and 5.3 (grid) during storage. Vertical bars represent standard deviations. 


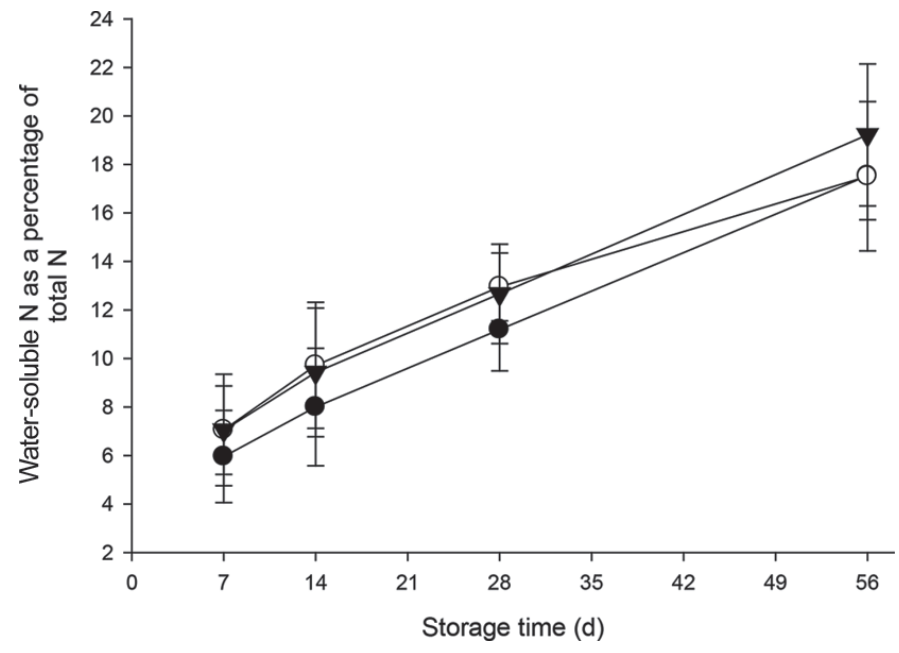

Figure 3. Water-soluble nitrogen as a percentage of total nitrogen for White cheeses packed at $\mathrm{pH} 4.7(\bullet), 5.0(\bigcirc)$, and $5.3(\boldsymbol{\nabla})$ during storage. Vertical bars represent standard deviations.

DM content of the cheeses packed at $\mathrm{pH} 4.7$ led to a harder structure than the cheeses packed at $\mathrm{pH} 5.0$ and 5.3. Although the $\mathrm{pH}$ values among cheeses were not statistically different, the slightly (numerically) lower
$\mathrm{pH}$ values of cheeses packed at $\mathrm{pH} 4.7$ were likely to affect the hardness of these cheeses compared with the cheeses packed at $\mathrm{pH} 5.0$ and 5.3. As a result of TPA, no statistical differences $(P>0.05)$ were observed in the adhesiveness and cohesiveness of the cheeses (results not shown). However, in the sliceability test (i.e., large deformation), the adhesiveness of the cheeses packed at $\mathrm{pH} 5.0$ and 5.3 were significantly increased $(P<$ $0.05)$ with storage time $(\mathrm{r}=0.98$ and 0.91 , respectively; Figure 5). Cheese packed at pH 5.3 exhibited more adhesive $(P<0.05)$ structure in the sliceability test than the cheese packed at $\mathrm{pH} 4.7$ after 2 wk of storage. Packing cheeses at high $\mathrm{pH}$ values led to the formation of a soft and sticky texture that local cheese producers define as "Turkish delight like."

The sizes and weights of cheese crumbs that occurred during the sliceability test are given in Figure 6. Cheese with packing $\mathrm{pH}$ of 5.0 led to the formation of smaller crumbs than the cheeses packed at $\mathrm{pH} 4.7$ at 1 and 4 wk. Cheese packed at $\mathrm{pH} 5.3$ produced smaller crumbs during slicing compared with cheeses packed at $\mathrm{pH} 5.0$ and 4.7 at 8 wk of storage. No correlation was observed between the packing $\mathrm{pH}$ and the crumb sizes of the experimental cheeses (Figure 6).

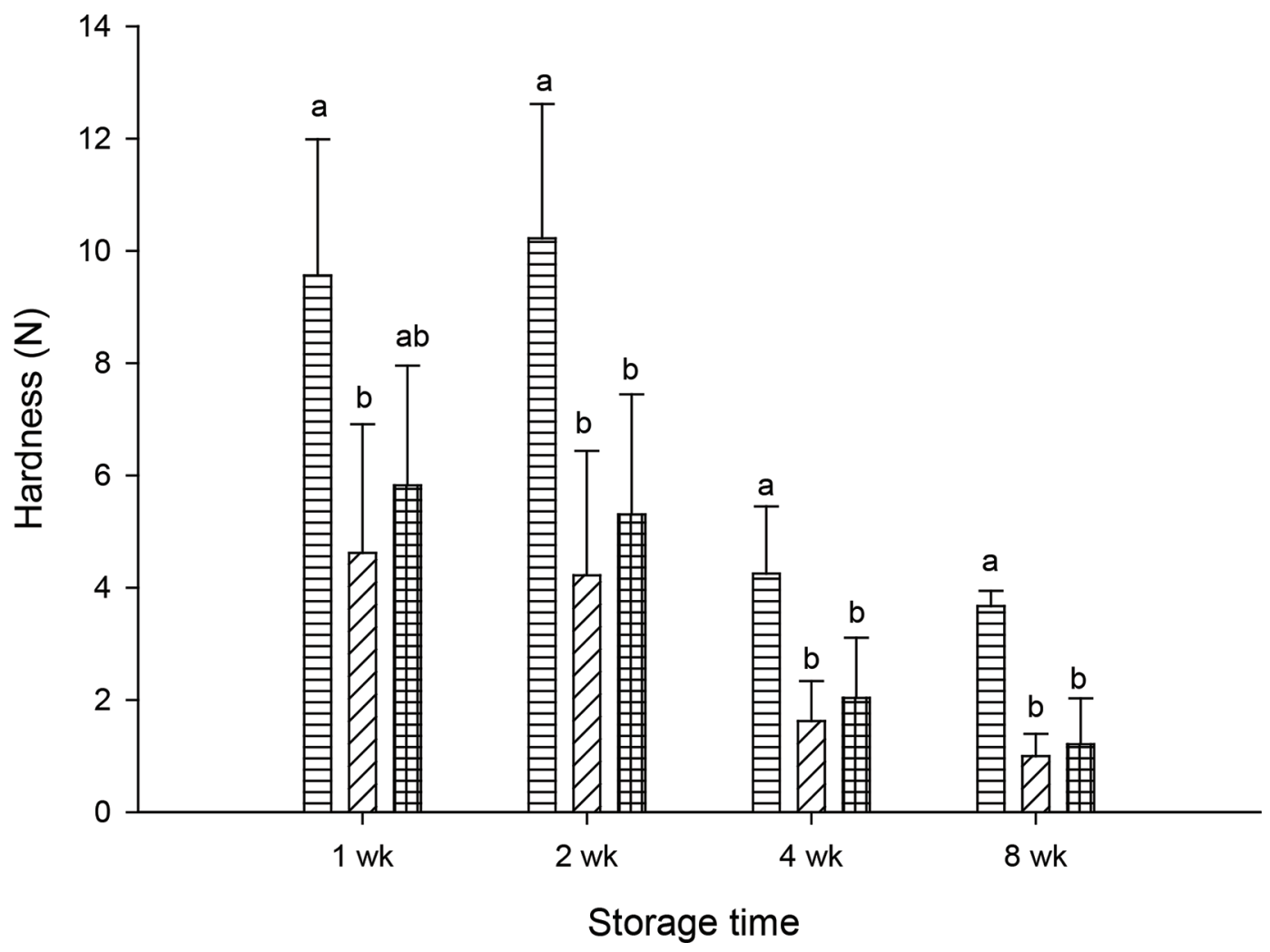

Figure 4. Hardness from texture profile analysis testing (30\% compression) for White cheeses packed at pH 4.7 (horizontal lines), 5.0 (diagonal lines), and 5.3 (grid) during storage. Vertical bars represent standard deviations. Values in the same storage time with different letters (a, b) are different $(P<0.05)$. 


\section{Storage time}

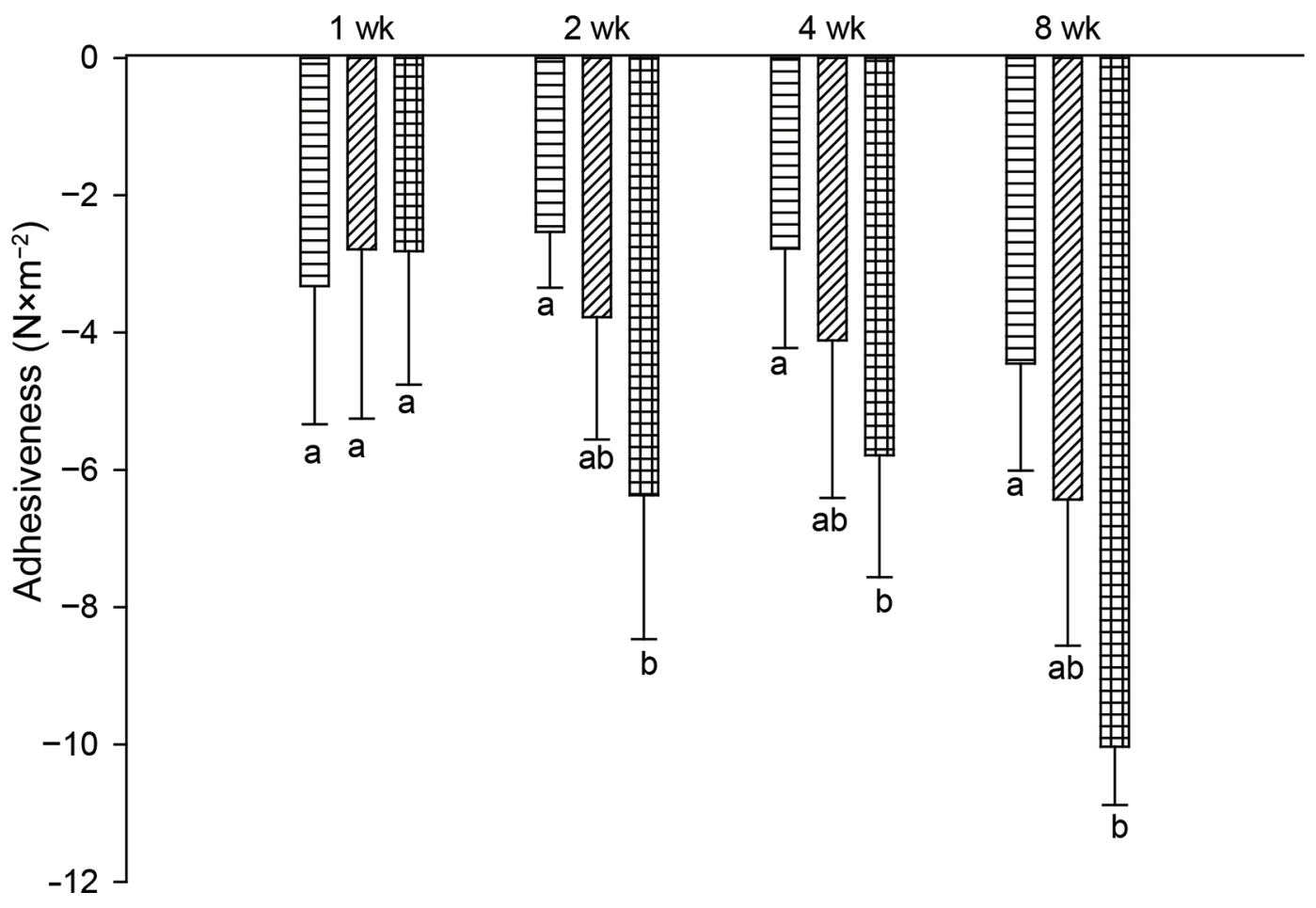

Figure 5. Adhesiveness from slicing test for White cheeses packed at pH 4.7 (horizontal lines), 5.0 (diagonal lines), and 5.3 (grid) during storage. Vertical bars represent standard deviations. Values in the same storage time with different letters $(\mathrm{a}, \mathrm{b})$ are different $(P<0.05)$.

Cheeses that were packed at $\mathrm{pH} 5.3$ had a lower crumb weight during slicing compared with cheeses that were packed at $\mathrm{pH} 4.7$ at 1,2 , and $4 \mathrm{wk}$ of storage. A significant negative correlation $(\mathrm{r}=0.63)$ was observed between the crumb weight and the $\mathrm{pH}$ values of the cheeses. It is known that mechanical openings (i.e., empty spaces) formed during cheese manufacturing increases cheese fracturability (Akbulut, 2012). The softer texture of cheeses packed at higher $\mathrm{pH}$ values were likely to yield fewer mechanical openings during manufacturing and storage, leading to smaller crumb weights. In previous studies, cheese $\mathrm{pH}$ was reported to play an important role on the adhesiveness and cohesiveness of cheese (Akbulut, 2012). Akbulut (2012) stated that cheeses with high $\mathrm{pH}$ values exhibited better reforming ability after grinding, and formed more homogeneous cheese blocks with less mechanical openings compared with reformed cheeses with lower $\mathrm{pH}$ values.

\section{CONCLUSIONS}

Textural properties of White cheeses were affected by packing $\mathrm{pH}$ values. The increase in the packing $\mathrm{pH}$ values of the cheeses led to the production of softer and more adhesive cheeses. Increase in the packing $\mathrm{pH}$ of cheeses decreased the crumb weight that occurred with slicing, but no correlation was observed between the crumb sizes and packing $\mathrm{pH}$. Packing $\mathrm{pH}$ values of White cheeses did not affect the amount of CCP and the rate of proteolysis during $8 \mathrm{wk}$ of storage. To our knowledge, this study is the first study to investigate the CCP levels in White cheese during storage. Also, this is the first study that investigated crumb formation that occurs in White cheese during slicing.

\section{ACKNOWLEDGMENTS}

The authors thank the Gunesoglu Sut Gida San. Tic. A.S. and Elif Sut Urunleri for making their facilities available for the cheese making conducted in this study. We also thank Referans Gida San. ve Dis Tic. Ltd. Sti for their donations of starter cultures used in this study. The financial support of The Scientific and Technological Research Council of Turkey (TUBITAK), Ankara, Turkey (grant no. 2150651), is greatly appreciated. The authors have not stated any conflicts of interest. 


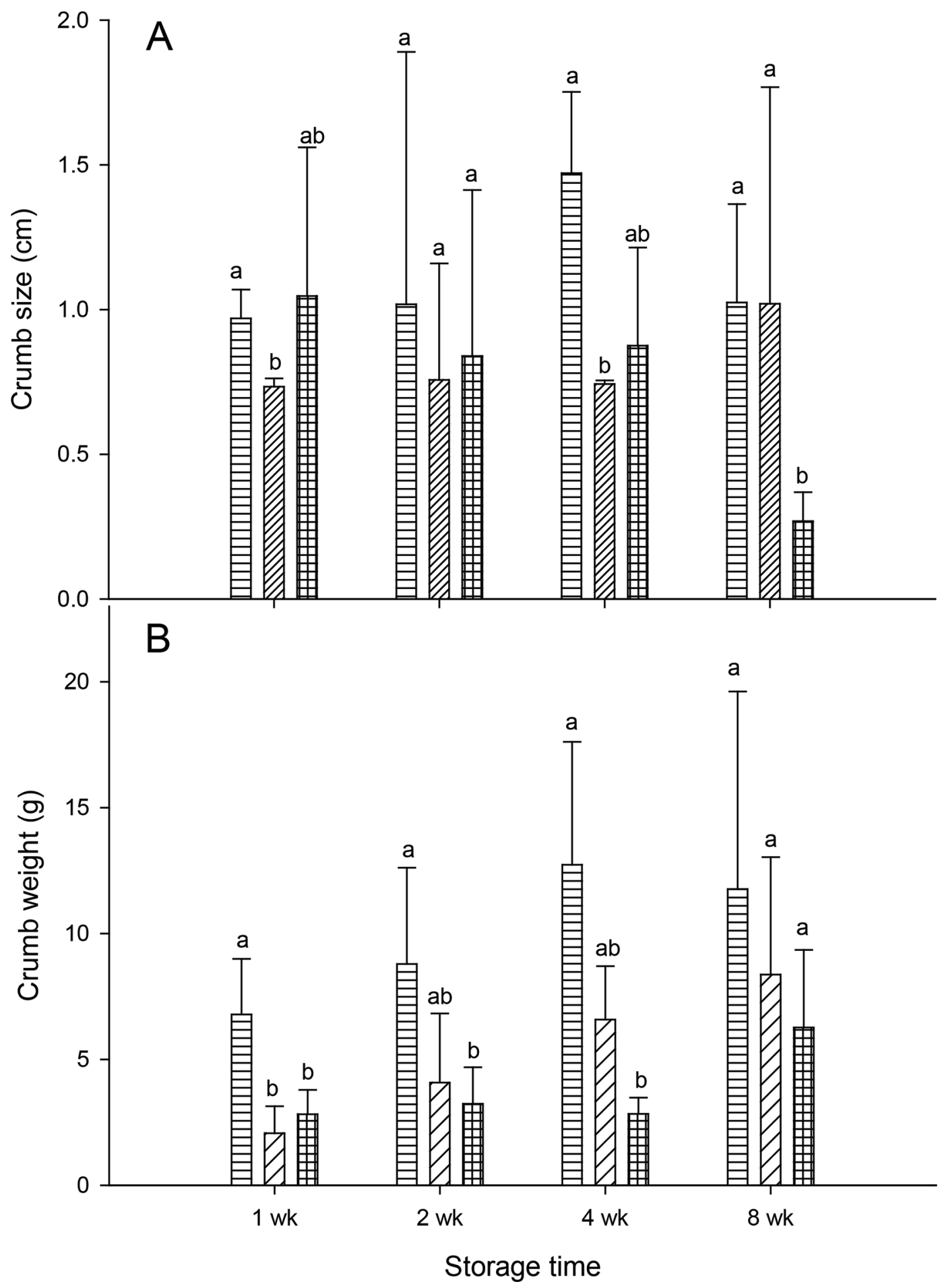

Figure 6. Crumb sizes (A) and crumb weights (B) from slicing test for White cheeses packed at pH 4.7 (horizonal lines), 5.0 (diagonal lines), and 5.3 (grid) during storage. Vertical bars represent standard deviations. Values in the same storage time with different letters (a, b) are different $(P<0.05)$. 


\section{REFERENCES}

Akbulut, C. 2012. A study on the impact of physical disruption and reforming on cheese texture. $\mathrm{PhD}$ thesis. University of Wisconsin, Madison.

AOAC International. 2007. Official Methods of Analysis. 17th ed. AOAC International, Arlington, VA.

Grappin, R., T. C. Rank, and N. Olson. 1985. Primary proteolysis of cheese proteins during ripening. A review. J. Dairy Sci. 68:531540. https://doi.org/10.3168/jds.S0022-0302(85)80855-9.

Hassan, A., M. E. Johnson, and J. A. Lucey. 2004. Changes in the proportions of soluble and insoluble calcium during the ripening of Cheddar cheese. J. Dairy Sci. 87:854-862. https://doi.org/10 .3168/jds.S0022-0302(04)73229-4.

Hayaloglu. A. A., M. Guven, and P. F. Fox. 2002. Microbiological biochemical and technological properties of Turkish White cheese "Beyaz Peynir". Int. Dairy J. 12:635-648. https://doi.org/10.1016/ S0958-6946(02)00055-9.

Horne, D. S. 1998. Casein interactions: Casting light on the black boxes, the structure in dairy products. Int. Dairy J. 8:171-177. https://doi.org/10.1016/S0958-6946(98)00040-5.

Hwang, C. H., and S. Gunasekaran. 2001. Measuring crumbliness of some Queso Fresco-type Latin American cheeses. Milchwissenschaft 56:446-450.

Karami, M., M. R. Ehsani, S. M. Mousavi, K. Rezaei, and M. Safari. 2009. Changes in the rheological properties of Iranian UF-Feta cheese during ripening. Food Chem. 112:539-544. https://doi.org/ 10.1016/j.foodchem.2008.06.003.

Khosrowshahi, A., A. Madadlou, M. Ebrahim zadeh Mousavi, and Z. Emam-Djomeh . 2006. Monitoring the chemical and textural changes during ripening of Iranian White cheese made with different concentrations of starter. J. Dairy Sci. 89:3318-3325. https:// doi.org/10.3168/jds.S0022-0302(06)72368-2.

Kuchroo, C. N., and P. F. Fox. 1982. Soluble nitrogen in Cheddar cheese: Comparison of extraction procedures. Milchwissenschaft $37: 331-335$.

Lee, M. R., M. E. Johnson, and J. A. Lucey. 2005. Impact of modifications in acid development on the insoluble calcium content and rheological properties of Cheddar cheese. J. Dairy Sci. 88:37983809. https://doi.org/10.3168/jds.S0022-0302(05)73065-4.

Lucey, J. A., M. E. Johnson, and D. S. Horne. 2003. Perspectives on the basis of the rheology and texture properties of cheese. J. Dairy Sci. 86:2725-2743. https://doi.org/10.3168/jds.S0022 $-0302(03) 73869-7$
Metzger, L. E., D. M. Barbano, P. S. Kindstedt, and M. R. Guo 2001. Effect of milk preacidification on low fat Mozzarella cheese: II. Chemical and functional properties during storage. J. Dairy Sci. 84:1348-1356. https://doi.org/10.3168/jds.S0022-0302(01)70165 -8 .

O'Mahony, J. A., J. A. Lucey, and P. L. H. McSweeney. 2005. Chymosin-mediated proteolysis, calcium solubilization and texture development during the ripening of Cheddar cheese. J. Dairy Sci. 88:3101-3114. https://doi.org/10.3168/jds.S0022-0302(05)72992 $-1$.

Park, Y. W. 2000. Comparison of mineral and cholesterol composition of different commercial goat milk products manufactured in USA. Small Rumin. Res. 37:115-124. https://doi.org/10.1016/S0921 $-4488(99) 00144-3$

Pastorino, A. J., C. L. Hansen, and D. J. McMahon. 2003a. Effect of salt on structure-function relationship of cheese. J. Dairy Sci. 86:60-69. https://doi.org/10.3168/jds.S0022-0302(03)73584-X.

Pastorino, A. J., C. L. Hansen, and D. J. McMahon. 2003b. Effect of $\mathrm{pH}$ on chemical composition and structure-function relationships in Cheddar cheese. J. Dairy Sci. 86:2751-2760. https://doi.org/10 .3168/jds.S0022-0302(03)73871-5.

Sheehan, J. J., and T. P. Guinee. 2004. Effect of $\mathrm{pH}$ and calcium level on the biochemical, textural and functional properties of reduced fat Mozzarella cheese. Int. Dairy J. 14:161-172. https://doi.org/10 1016/S0958-6946(03)00167-5.

Topcu, A., and I. Saldamli. 2006. Proteolytical, chemical, textural, and sensorial changes during the ripening of Turkish White cheese made of pasteurized cows' milk. Int. J. Food Prop. 9:665-678. https://doi.org/10.1080/10942910500542238.

Wium, H., and K. B. Qvist. 1998. Effect of rennet concentration and method of coagulation on the texture of Feta cheeses made from ultrafiltered bovine milk. J. Dairy Sci. 65:653-663. https://doi .org/10.1017/S0022029998003094.

Zoidou, E., N. Plakas, D. Giannopoulou, M. Kotoula, and G. Moatsou. 2015. Effect of supplementation of brine with calcium on the Feta cheese ripening. Int. J. Dairy Technol. 68:420-426. https:// doi.org/10.1111/1471-0307.12199.

\section{ORCIDS}

K. Bulduk @ https://orcid.org/0000-0001-6228-4561

M. Ozturk ๑ https://orcid.org/0000-0002-3919-897X 